\title{
Main Document
}

\section{Title: “IT'S GOOD, THEY'RE LIKE ME; THE SAME BUT DIFFERENT." AN INTERPRETATIVE PHENOMENOLOGICAL ANALYSIS OF THE IDENTITIES OF WOMEN WITH DOWN'S SYNDROME}

Running Head: The Identities of Women with Down's Syndrome

\begin{abstract}
Background

For people with disabilities, identity formation is based on responses to hierarchical values determined by able populations. Some adopt a disability identity, whereas others may seek to conceal their disability. No research has focused on how women with Down's Syndrome form an identity.
\end{abstract}

\section{$\underline{\text { Design }}$}

Eight women with Down's Syndrome took part in semi-structured interviews designed to find out more about their individual and shared identities. The transcripts were analysed using interpretive phenomenological analysis.

\section{Findings}

Negative assumptions of others and oppressive, paternalistic care often lead to a lack of ownership over narratives. 'Finding a place in society' is an attempt to challenge this and gain a sense of ownership over their lives.

\section{Conclusions}

This research uncovered the individual and shared identities that women with Down's Syndrome construct. Services need to be aware of the role they have in supporting these women to develop autonomy and ownership over their lives.

Keywords: Down's Syndrome, Identity, Intellectual Disability, Women, Womanhood 


\section{Introduction}

\section{The Importance of Identity Development}

The concept of identity plays a fundamental role in understanding and interpreting human behaviour. As such, previous research has documented the positive benefits associated with commitment to an identity, including; higher levels of self-acceptance, environmental mastery, positive relationships and a sense of purpose in life (Vleioras \& Bosma, 2005). Furthermore, a key tenet of Social Identity Theory (Tajfel \& Turner, 1979) is that people strive to protect individual self-esteem by aligning themselves with certain groups. These groups form our social identities and thus in turn impacts upon our individual identity. In the event of an unfavourable evaluation, an individual may choose to reject a chosen social group in favour of another, more favoured group. This concept is known as social mobility and serves the purpose of protecting one's self-esteem.

\section{Disability Identity and Intellectual Disabilities}

Putnam (2005) describes disability identity as a concept whereby people who experience disability also experience solidarity and affinity with others who also have a disability. This appears to be a protective factor for those with disabilities and has been associated with lower levels of depression and anxiety (Bogart, 2015). For individuals with congenital disabilities, previous research has found that these individuals have higher levels of disability identity and subsequently higher levels of self-esteem (Li \& Moore, 1998; Bogart, 2014). Smart (2008) suggests that this may be because individuals with congenital disabilities have no premorbid identity. As a result, they may be more likely to consider their disability as an indivisible part of their identity and thus be more likely to accept it. However this begs the question, do you have to have experienced something in order to experience the loss of it?

Furthermore, disability scholars have also found that those with visible disabilities compared to those with hidden disabilities have also higher levels of disability and those with hidden disabilities were more likely to attempt to deny or conceal their disability in some way (Nario-Redmond, Noel \& Fern, 2013). 
In terms of ID, this can be considered both a congenital and hidden disability and so it is interesting to consider how and if current disability literature applies. As a result, this gives these individuals a degree of anonymity, which presents the dilemma of whether to disclose the disability. These individuals may constantly be making decisions on which identity to associate with (Valeras, 2010).

The label of ID could be considered hard to change, given the posited permanence of IQ (Harris 1995). For those who accept the diagnosis of ID, this may be considered an unwelcome label that is accompanied by feelings of shame (Kenyon, Beail \& Jackson, 2013). The evident discomfort with this label could be attributed to the potential negative repercussions of identifying with a socially devalued identity. Sinason (1992) suggests that individuals with ID are acutely aware of the prejudicial attitudes that exist in society and thus may develop coping strategies that help to distance themselves from this stigma. Some individuals may conceptualise their ID as mild compared to others in order to distance themselves from the discomfort of the label and present themselves as having strengths and requiring less support than other people with ID (Findlay \& Lyons, 2000; McVittie, Goodall \& McKinlay, 2008).

On the whole, it is evident that having a diagnosis of ID can be associated with infantilising, bullying, shame and stigma and a common coping mechanism is to distance oneself from this stigmatising label by striving to appear "normal" (Kenyon et al., 2013). The evident internalisation of stigma relates to what Goffman (1963) termed "self-stigma." This refers to the process by which an individual endorses cultural biases and stereotypes pertaining to a particular group and applies them to oneself. Current research suggests that individuals with ID tend to internalise the negative attitudes held by wider society and thus develop copings strategies to manage this.

\section{Womanhood}

Stigma plays a significant role within the lives of women with disabilities in several areas of their life, such as rarely being perceived as nurturing by the general public and assumed to be unfit parents (Nario-Redmond, 2010). Specifically with regard to sexuality, Howland and Rintala (2001) concluded that a group of women with disabilities appeared to have internalised the view that they are "damaged goods" and as a result, this posed a serious
Commented [L2]: Added in line with reviewer 2's recommendation

Commented [L3]: Section has been made more concise, included wider aspects of identity and commented on the potential "double hit" that women with ID may experience in line with reviewer 1's recommendations 
threat to their self-worth. Looking at identity more widely, in a qualitative study by Mejias, Gill and Shpigelman (2014), women with disabilities tended to internalise the pity expressed by others frequently causing them to feel devalued. Thus, they struggled to develop a positive self-concept.

Women with ID often experience exclusion from families, are often prohibited from having relationships and are rarely involved in meaningful occupation (Traustadottir \& Johnson, 2000). When they were explicitly asked about their sexuality, women with ID presented themselves as non-sexual beings who viewed sex as disgusting and dirty (Fitzgerald \& Withers, 2013). Furthermore, when asked more broadly about womanhood and identity, the woman's role was described by participants as a caring role, with men's responsibilities being to work and provide for others. Men were perceived as more important and powerful and the women struggled to formulate a positive view of themselves. In a study exploring contraceptive use, women with ID felt that they had little control over decisions regarding contraception. These decisions were viewed by the women as the responsibility of others around them (McCarthy, 2010).

Mothers with ID frequently report being treated as children, despite being parents, and their abilities are frequently compared to others (Gould \& Dodd, 2014). They are often assumed to be incompetent and the result of this was summed up in a quote from research by Gould and Dodd (2014); "normal people can have a child but disability can't." Further, mothers with ID reported never expecting to be exclusively responsible for their child's care (Mayes Llewellyn \& McConnell, 2011).

Similarly to Fitzgerald \& Withers, Scior (2003) found that women with ID frequently described themselves in line with a traditionally stereotypical view of what it means to be a woman. Furthermore, the women viewed men as superior to women. In addition to this, the women spoke of being treated as children and thus dependent upon non-disabled others. The theme of paternalism and feeling controlled is something that also haunts the language of men with ID (Azzopardi-Lane and Callus, 2015; Wilkinson, Theodore and Raczka, 2015).

When considering identity development in those with ID, samples are often male dominated and thus the voices of women are lost. Current understanding of identity issues for women 
with ID come from research into topics such as sexuality and parenthood. There is a scarcity of research that has specifically looked at identity development in women with ID as a whole and independent of sexuality.

Coleman, Brunell, Haugen and Curr (2015) examined attitudes towards disabled men and women and found that participants reported more of a desire for social distance from intellectually disabled women than physically disabled women. Interestingly, evaluations of men were not affected by the type of disability. This would suggest that women with intellectual disabilities are doubly disadvantaged due to being discriminated against for both their gender and disability. In light of this, it is perhaps therefore not surprising that the negative attitudes of society are present within the narratives of these individuals.

\section{Down's Syndrome}

It has been estimated that Down's Syndrome (DS) is prevalent in 14 of every 10,000 live births (Parker et al., 2010). People with DS often experience some degree of ID, however there are a couple of factors that prevent the existing literature for this population from being fully applicable. One of the resultant manifestations of DS is physical characteristics such as; a flat nasal bridge, short stature, shortened fingers and toes and skin folds of the upper eyelid (Roizen \& Patterson, 2003). These phenotypical characteristics mean that DS is considered a visible disability, therefore, these individuals have very little opportunity to conceal their disability, which perhaps leaves them open to the preconceived judgements of others. As a result they may not have the option of concealing their disability as other with ID might and so the applicability of the aforementioned research is questionable.

Another point to consider is the impact of prenatal testing, something that is not widely implemented for foetuses suspected of having an ID. Recent qualitative research has found that this procedure has led to those with DS believing that DS is a negative and devalued condition. The introduction of prenatal testing, for some, has raised painful questions about whether they are wanted within society (Barter, Hastings, Williams \& Huws, 2016). Thus, understanding how individuals with DS conceptualise their identity in light of these issues seems pertinent yet relatively unknown.

\section{Identity Development and DS}

Commented [L5]: More added about the physical characteristics of DS which makes it a visible disability and this previous research may not apply. Another factor is prenatal testing and the impact this has on individuals with DS - added in line with reviewer 1's recommendations 
In order to understand the identities of individuals with DS, Seale (2001) analysed the content of online, personal webpages of individuals with DS. Seale describes the way DS is accepted by the page owners as either general acceptance or acceptance of the label with certain conditions. General acceptance was typified with phrases such as "I am Down's Syndrome" and "I was born with Down's Syndrome." Qualified acceptance of this label was typified by statements such as "I am a person before I am someone with Down Syndrome" and "I might have Down Syndrome but I can do the same things as you." These phrases suggest that in addition to not denying the label, these individuals were attempting to convey that they are not less worthy than other people.

Cunningham and Glenn (2004) implemented a photograph sorting exercise in order to understand the self-perceptions of individuals with DS. They concluded that participants had little awareness of their diagnosis. However one could argue that the use of photograph sorting does not provide insight into the reason for this or the identities that these individuals do identify with. Interestingly, some similarities with aforementioned research were found in a study undertaken by Brown, Dodd and Vetere (2010). With regard to identity, no one spoke of having DS or a disability but spoke of stereotyped identities such as men doing the gardening, being a builder and going to the pub. Notably, this research sampled more male participants, as appears to be common within the literature. However, participants still held stereotypical beliefs about gender roles, which leads us to consider whether this is something that is unique to women with ID/DS or more common across this population.

\section{Aim of present study}

Little research exists to help us understand how women with DS conceptualise their identity. Given that they do not necessarily have the option of trying to "pass" in society; current research fails to provide understanding into this topic. The current evidence base provides little understanding regarding the meaning that these individuals attach to DS and how their identity is successfully negotiated in light of psychosocial disadvantages. Considering that professionals have so much control over the most intimate areas of these women's lives, it may be that they have a limited sense of womanhood and a heightened sense of being powerless. How can we expect a woman with ID to develop an identity as a woman if this is the case? The aim of this research was to explore the experiences of women with DS using a 
qualitative approach in order to understand how these have impacted upon their individual and shared identities.

\section{Method}

\section{Participants}

Eight women with Down's Syndrome were recruited from community ID teams in the NHS. The women varied in their living contexts; two lived alone, two lived with their parents and four lived in group residential settings. All participants were supported on a daily basis by support workers, however the intensity and frequency of this varied. The mean age of participants was 35 years (range 21-49 years). Demographic details of participants are provided in Table 1; all names are pseudonyms. All women who were approached to participate did so. No potential participants were approached if it was felt that they did not Commented [WU6]: Pseudonym details added in line with have the capacity to provide informed consent at the time of recruitment

Table 1.

Pseudonyms and ages of participants

\begin{tabular}{lcl}
\hline & Pseudonym & Age (years) \\
\hline Alice & 21 \\
Claire & 34 \\
Debbie & 44 \\
Jayne & 35 \\
Katie & 28 \\
Natalie & 28 \\
Patricia & 49 \\
Rebecca & 38 \\
\hline
\end{tabular}




\section{Recruitment and Procedure}

Potential participants were approached by their lead clinician and informed of the research, then given the opportunity to read through the information sheet if they expressed interest. Consent was sought for the primary researcher (EG) to contact the participant. Purposive sampling was adopted due to the focus of IPA on understanding specific phenomena for specific groups of individuals.

Time was spent prior to the interview to review the information sheet and sign the consent form, and participants were encouraged to ask any questions they may have of the researcher. Participants were interviewed on NHS premises and participants had the option of being interviewed alone or with someone else to ensure they felt as comfortable as possible. Only one participant chose to be interviewed with a staff member. Interviews lasted between 25 and 55 minutes and were audio recorded and transcribed, with all identifiable information removed or changed. Initial questions were more general and included questions such as "how would you describe yourself?" As the interview progressed and rapport was gained, questions were more specific such as "Can you tell me what it is like having ID/DS?" In accordance with the framework proposed by Smith, Flowers and Larkin (2009), prompts were provided in order to encourage further information. Prompts included questions such as "can you tell me a bit more about that?" and "how did that make you feel?"

Transcripts were analysed using Interpretative Phenomenological Analysis (IPA) and the steps outlined by Smith et al. (2009). IPA was chosen as it adopts an existential approach to qualitative research that aims to uncover the "insider's perspective" and explore the lived experiences of participants (Van Manen, 1997). In contrast, while also inductive, Grounded Theory seeks to establish a new explanatory theory of social processes based on the data. In this study the focus was on the lived experience of how participants navigate the contributory factors to the formation of their identity, not on the development of another identity theory. IPA starts with, but should go beyond, a standard thematic analysis, which is used typically with data not as deep or rich (Brocki \& Wearden, 2006). While each analytic approach has its own strengths, the approach "shapes how one frames research questions, attends to data and their meaning, and draws conclusions based on the analysis" (Starks \& Trinidad, 2007). Within IPA, it is widely accepted that the researcher is unable to experience the same
Commented [L7]: Changed from "homogenous groups of individuals" in line with method point 1 from reviewer 1.

Commented [WU8]: More detail of the rationale for IPA given in light of recommendation point 1 from reviewer 2 
experiences as participants. Thus by researching the lived experiences of participants, we can move away from subjective speculation and understand how events have been experienced.

While data analysis was undertaken predominantly by one author (EG), a number of transcripts were coded again (blind) by a second author (KR) to verify themes. All three authors were involved in the naming and grouping of themes as the analysis progressed. To provide further confidence in the validity of the findings, participants were invited to take part in member checks following data analysis. All participants were contacted and invited, however only Alice and Jayne chose to attend participant validation sessions. These were face-to-face interviews, in which the themes were presented in written format and fully explained.

\section{Ethics}

Ethical approval for this research was granted by a local NHS Research Ethics Committee and the Research and Development Department of the host NHS Trust.

\section{Results}

Four superordinate themes emerged from the data analysis: 'assumptions of others', 'oppression', 'lack of ownership over own narrative' and 'finding a place in society.' These superordinate themes comprised 11 subordinate themes and each subordinate theme was evidenced with data from at least half of the participants in line with recommendations from Smith et al. (2009).

\section{Negative assumptions of others}

Each of the participants reported experiencing negative reactions from others at some point in their lives and this often took the form of discrimination. The women demonstrated internalisation of these views and so their narratives are dominated by these assumptions of others. This culminated in an identity that appeared to be co-constructed and based upon the assumption that they are an unvalued population. Rebecca describes the meaning she derives from these experiences;
Commented [WU9]: Added in response to reviewer 2's comments to provide more information about data validation

Commented [WU10]: Added to provide more information about the participant validation in accordance with reviewer 1 's recommendation.

Commented [L11]: Added in line with Results commen from reviewer 1 
Rebecca: Sometimes they don't talk to me, they just look at me, it's weird. I don't know why. Makes me think they don't take me seriously or really care.

Despite the negative messages received from society, the women demonstrated firmly held beliefs about themselves that contradict the views of others. Some participants spoke of how they are often presumed incompetent by others as a result of having DS demonstrating a disparity between how they view themselves and how they perceive to be viewed by others;

Katie: I'm a person who has got a learning difficulty problem with Down's Syndrome, but outside this world I don't think I am like that at all. I'm a person in my own right, to say what I want in my life and I am able to think and be a bit more aware than people think. Because I'm different, sometimes they discriminate me for who I am

Patricia spoke of the need to prove her abilities as a result of others' inaccurate assumptions regarding her skills;

Patricia: I can look at magazines, it's hard to read them sometimes but I can still read them a bit. People don't think I can read or, um, write but I tell them, I tell them I can.

The women's responses indicated a tendency to internalise the views of others and identify as individuals who are perceived as incompetent and unvalued by society because of their diagnosis of DS.

\section{Oppression}

This superordinate theme refers to the impact of the behaviours of others within the participants' social contexts that arise as a result of inaccurate, negative assumptions. A general lack of responsibility and autonomy appears to be afforded to these women and as a result, there seems to be a reluctance to challenge this. The majority of the women felt unheard by others around them and each of them had their own interpretation as to why this happens. 
Jayne: Yeah 'cause some people don't listen

Interviewer: Don't they?

Jayne: No, just like, feels like you don't count, you not listened to.

For some, the presence of a speech impediment is often a barrier to communication that causes a great deal of embarrassment. For these individuals it would appear that they do not voice their opinions as often as they would like, so as to protect themselves from the humiliation of not being understood. Debbie reported an upsetting experience of not being understood that caused a great deal of embarrassment;

Debbie: Yeah like this girl once, I was talking and she was like "What? What?" Made me embarrassed and made me not want to talk.

The women communicated the belief that they often have to ask permission from others before making decisions, suggesting that these women hold doubts regarding their own autonomy. They also found that decisions were often made on their behalf. This was apparent when Katie spoke of once having a boyfriend:

Katie: Yeah didn't feel right, people getting involved, like the staff, his staff they were like saying things, not always letting me see him, saying it wasn't right for me. Now I would just rather be with my family.

Despite often having decisions made on their behalf, sometimes without their full agreement, there was little evidence to suggest that the women actively challenge this paternalistic care and instead comply with the rules of others.

The majority of the women spoke of how others very rarely share important information with them, particularly regarding their physical health diagnoses. When discussing a physical health difficulty Jayne spoke of how she was not provided with information regarding procedures and medication;

Interviewer: What were the tablets for? 
Jayne: Don't know, didn't say, just that I was, I was poorly so the doctor gave them to me.

There was a degree of acceptance amongst the women that knowledge regarding issues such as physical health and diagnoses lies with those who support them. Although the women spoke of having little knowledge of these issues, there was no indication that they would (or perhaps could) challenge this and obtain this knowledge for themselves.

\section{Lack of ownership over own narrative}

This superordinate theme emerged as a product of oppression, which in itself results from the assumptions of others. The women presented disjointed and unclear accounts of their identity, perhaps due to lack of opportunity to explore this for themselves. The results suggest that being asked about identity is a rare occurrence for these individuals, this was evident in their surprise and confusion when asked about their personality.

Interviewer: Can you possibly tell me some things about yourself and what you're like?

Rebecca: You want to know some things about myself?"

For Patricia, she sought the answer to this type of question from the researcher. This potentially highlights a doubting of her own voice, uncertainty as to how to answer the question or perhaps a desire to comply with the researcher's opinions despite having only just met.

Interviewer: What can you tell me about yourself?

Patricia: I'm not shy, I'm not, erm, oh I don't know, what do you think?

For some, it was evident that the language of others around them infiltrated the language that they used to describe themselves. This raises questions as to how much of their identity was self-constructed and how much was reliant upon the opinions of others.

Patricia: Sometimes I get bad tempered, I get agitated easily, what does that mean? Interviewer: Well, what does agitated mean to you?

Patricia: Don't know, the staff say it. I do, I get errm agitated though. 
All of the women who took part in this research demonstrated a distinct lack of knowledge regarding DS. The narratives that were expressed were littered with confusion, misunderstanding and attempts at making sense of the relatively little information that is available to them. For some, DS is a diagnosis given to them by others but appears to be rarely understood and this was evident in Debbie's response:

Debbie: “Down's Syndrome it's like, it's disability but it's confusing. I don't know what it is."

Jayne demonstrated some understanding but was unable to elaborate on this further, which begs the question as to who owns this narrative:

Jayne: It must be when you're like something in your head.

Interviewer: Something in your head?

Jayne: Yes, something wrong in your head, that might be it maybe.

Finding a place in society

Finding where we fit within certain social groups and wider society is a phenomenon well studied within social psychology literature. Numerous scholars have written about the value and emotional benefits of belonging to groups and conversely the damaging effects of belonging to a stigmatised group (Tajfel \& Turner, 1979; Zolkowska, \& Kaliszewska, 2014). The participants in this research were no different, however there were differences in the ways in which they negotiated their affiliation with certain categorisations.

For a population who are so often viewed as individuals who require help and support, for these women, being the ones who provide help to others formed an important part of their identity. For some, it seemed to bring about a sense of self-efficacy and altruism that challenges the stigmatised views of others, this was clear within Debbie's interview:

Debbie: Because it's a good thing, to help, it's good to help others, and, and then you go and teach other people it and they'll teach their friends and their family. 
The helper role may also generate an alignment with staff, which for some may bring about distance from the part of themselves that they see as different and unvalued. Jayne's response appears to highlight this and demonstrate an attempt to identify with those who are more able, i.e. the staff:

Jayne: I help the staff, like to make the games and like to help people who can't do things. I, l like to be helping with the staff. I help the staff to help other people who can't do it.

Numerous comparisons based on social competence were made by each of the women. They seemed to serve the purpose of highlighting the participants' abilities in relation to her peers. This was evident for Patricia when discussing her experiences of having ID and DS. She introduced discussion regarding peers' difficulties perhaps to distance herself from the negative ascriptions of ID and to identify by comparison, her own strengths.

Patricia: Some people with disabilities they are swearing and shouting, a lot, um they are. Can't control themselves. I'm not like that.

When asked about their own identities, many of the women would highlight skills that they had, that others with an ID/DS do not, therefore emphasising difference and creating a contrast group.

Natalie: We do different jobs, some people are not good at all jobs. I am good at lots of jobs like wiping the tops and I don't need help all of the time. Some people they need help all of the time though, they need more help.

By highlighting their abilities and contrasting these with the difficulties faced by their peers, the women seemed to distance themselves from the negative ascriptions that are so often associated with having DS and ID.

Additionally, the women appeared to have quite restricted views of the possibilities and opportunities that are available to them, choosing to define a woman by stereotyped interests 
and hobbies. These may be stereotypes that are reinforced within their social contexts, however, these may be the roles and standards that these women feel they have to fulfil in order to find a valued place within society. For many of the participants, defining what it means to be a woman was difficult. However, some defined being a woman as having to keep a tidy appearance and wear feminine clothing.

Rebecca: Yeah I think women like dressing up all gorgeous, do the make-up and hair and like picking out nice things like skirts to make them look dressy and gorgeous to impress the men.

The desire to be 'normal' was expressed by the majority of the women, perhaps as a direct result of the messages they receive from society regarding their value. For some, having DS exacerbated feelings of difference and automatically classifies them as not being normal.

Alice spoke of how she believes normality can be obtained. For her this included taking part in lots of activities and keeping busy. By demonstrating competence and engaging with many hobbies, Alice strives to distance herself from the abnormality of DS and find her place in society as a 'normal' individual.

Alice: Yes. Sometimes so the surgery is to make them like better, like, like, like yeah normal

Interviewer: The surgery makes them normal?

Alice: Errm well like the surgery a bit yeah. But Down's Syndrome, they like have to do lots of things and then they'd be like perfect. Like dancing, singing, music and things.

This belief was echoed by Jayne who expressed that by learning skills and demonstrating competence, one can challenge the assumptions of others and adhere to the socially constructed idea of normality:

Jayne: Yes, they teaching you to be independent because people with disabilities they need to learn skills to do normal things and to do things for themselves, to be like independent. 
The negative assumptions and misconceptions of others are often internalised by women with DS leading to feelings of abnormality. This message is reinforced throughout the women's lives and so to escape these painful judgements, they strive to challenge assumptions and by adhering to what is socially valued within western culture; the ability to meaningfully contribute to society.

\section{Participant Validation}

Participants were invited to take part in member checks following data analysis. Alice corroborated each of the superordinate themes and added examples to support the subordinate themes. When discussing the negative assumptions of others, Alice made reference to her own abilities and also the inabilities of her peers. This strengthened the evidence for the link between finding a place in society in order to challenge the assumptions of others. Jayne spoke most about her confusion as to why others are reluctant to provide her with information and linked this to her lack of understanding of DS. This conversation indicated how oppressive practice can inadvertently inhibit development of a cohesive self-narrative for these individuals.

\section{Discussion}

The analysis revealed that each of the women had often been on the receiving end of numerous negative and stigmatising experiences throughout their lives. The theme "assumptions of others" highlights how the negative narratives of society are often internalised by women with DS. It is these assumptions and misconceptions of others that perhaps leads to oppression, which in turn reinforces the women's negative beliefs and makes them feel unheard. As a result of both of these themes, it was clear from the analysis that the women did not appear to have ownership over the narratives that they presented. Finding a place in society indicates the day to day struggle and importance that these women place on challenging these assumptions and oppression and negotiating their role within society.

The women demonstrated an internalisation of the assumptions of others. This internalisation of stigma echoes findings elsewhere in the literature, suggesting stigma can negatively impact upon the ability to develop a positive self-concept (Howland \& Rintala, 2001). This finding 
was also documented by Gould and Dodd (2014), who found that women with ID also feel unvalued within society and this finding also stretches to women with physical disabilities (Mejias et al., 2014). This may not be unique to women however, as research has also shown similar themes for men with ID (Kenyon et al., 2013).

A sense of powerlessness was strong within the themes and the women showed little inclination that they would or could challenge this, perhaps as a result of oppression. Lack of access to appropriate information and resources as well as a lack of opportunity to discuss issues related to identity development were not only highlighted in the current research but also within research by Azzopardi-Lane et al. (2015). This would suggest that these issues are not necessarily unique to women with DS.

The repeated lack of opportunity to explore identity culminated in identities that were somewhat confused and disjointed. Very few of the women could provide a definition of what ID/DS meant to them and, as Patricia demonstrated, often found it to be a confusing diagnosis to understand. This fits with findings from research by Beart, Hardy \& Buchan (2004), who found when interviewing individuals with and ID about their experiences of advocacy groups that participants did not know the meaning of ID. These findings are also reflected in research by Monteleone and Forrester-Jones (2016) who found that individuals with ID experience feelings of difference but struggle to make sense of this and the terminology others impose upon them. As a result, they feel obliged to behave in accordance with societal expectations and thus individual identity exploration is inhibited. This suggests that these individuals form a population who have an inescapable label imposed upon them and reinforced by society, but have little opportunity to challenge, explore or understand it for themselves.

Each of the women demonstrated different ways of negotiating their identity in order to make sense of who they are, including attempts to fulfil a helper role and make comparisons with less able peers. Previous research by Findlay and Lyons (2000) revealed similar results in that individuals made judgements and comparisons with others based on competence and ability. Rapley, Kiernan \& Antaki (1998) posited that people with LD might manage their identity by presenting alternative "competencies" by demonstrating knowledge of specific topics or claiming membership of higher status groups. Social Identity Theory seems particularly

Commented [L14]: Monteleone paper added in to compare very similar findings from recommendations of reviewer 2 
pertinent here, as this creation of in groups and out groups may represent an attempt to distance oneself from a socially unvalued group and protect one's individual self-esteem. Interestingly, these findings are not uncommon for marginalised groups such as those from ethinic minorities or those with mental health problems. Crocker and Major (1989) found that when one identifies with a stigmatised group, downward comparisons are made so as to promote positive self-evaluation. These comparisons are largely in-group and based on capability or wellness.

\section{Clinical implications}

Research has shown how those who struggle to form a clear sense of identity that they feel comfortable enough to share, are at higher risk for negative psychosocial outcomes (Cakir, 2014). The current research highlights a population that could be considered 'at risk' in relation to the outcomes associated with struggling to form an identity. Therefore, service providers and those who work with women with DS need to take a more proactive approach and give people opportunities to explore their identities for themselves.

This research has highlighted how individuals and services can shy away from discussions that may be painful for women with DS and withhold information from them. This may include withholding information about diagnoses or avoiding discussions about the impact of discrimination. A clear implication from this research is the need for more open discussions about the negative impact of having ID/DS and associated difficulties.

A further finding from this research was that the women often experience paternalistic care that they feel they have little/no control over and therefore do not feel they can challenge these decisions. In order to counteract this and empower women with DS, it would be beneficial for them to have an active role in the creation of care plans and risk assessments. These should be in a format that is meaningful to the individual and by collaboratively designing these documents, the women can take charge of their support and regain some control over their lives.

A clear message that was conveyed within the interviews was that the voices of these women are often lost, unexpressed and unheard. Advocacy groups for people with ID can be an

Commented [L15]: Findings have been compared to wider reviewer 2 
advantageous way for them to feel empowered, exert control over their lives and improve self-esteem (Wehmeyer \& Garner 2003; Gilmartin \& Slevin, 2010). Increasing the number of advocacy groups and offering these opportunities to women with DS may be one way of overcoming some of the difficulties highlighted within this research.

\section{Limitations}

There was a degree of sample bias within this research. All participants were White British and so their experiences and opinions reflect those from a western culture. Views and assumptions regarding DS may differ across cultural contexts. In addition to this, each of the participants were recruited from various community mental health teams. Thus, there is some assumption that these individuals were in receipt of support for mental health difficulties and may be more familiar with talking about themselves and their experiences. In addition, there is a risk that the sample is skewed towards those who have experienced more stigma and prejudice. The experience of living with DS without input from mental health teams may be more nuanced and potentially more positive and so research needs to be conducted outside of clinical settings. As the research was designed to be an open exploration of the most salient aspects of identity, sexual identity was not specifically explored. Nevertheless, previous research has indicated a number of difficulties with forming a sexual identity for these individuals. Thus, one should not assume that the absence of this concept within the results indicates a lack of salience, but perhaps a reluctance to discuss something that is often denied or forbidden.

Furthermore, the theme of compliance and lack of challenging others was apparent within the transcripts. Given that individuals with ID can often answer in a socially desirable manner (Finlay \& Lyons, 2001; Jobson, Stanbury, \& Langdon, 2013), this can raise questions as to the reliability of the data obtained through interviews and member checks. With regard to data analysis, the themes that have been extracted were based on the researcher's interpretations. Despite every attempt to implement rigour and transparency, it is noteworthy that a different researcher may have reached different conclusions. Validation aimed to overcome this to a certain degree through the use of triangulation and member checks. Nevertheless, the data should be considered as one interpretation of the data rather than a definitive truth.

Commented [L17]: References added in in relation to reviewer 1's recommendations
Commented [L16]: Added in in light of reviewer 1's recommendations 


\section{Conclusions and future research}

It was evident from this research that misconceptions and stigma shape how the women make sense of their identity and the narratives that they use. For some, the language of others was internalised, leading to negative beliefs and a struggle for form an assimilated identity that they held ownership over. These experiences appeared to trigger a set of behaviours and responses that helped the women to find a valued place in society in spite of their unwanted, unvalued label. This evidence base is very much in its infancy and so more, qualitative research is needed to further understand the identities of women with DS. More specifically, capturing the experiences of those who are not in receipt of mental health services would provide a broader and perhaps more nuanced understanding of the identities of women with DS

\section{References}

American Psychiatric Association. (2013). Diagnostic and statistical manual of mental disorders (5th ed.). Arlington, VA: American Psychiatric Publishing.

Azzopardi-Lane, C., \& Callus, A. (2015). Constructing sexual identities: People with intellectual disability talking about sexuality. British Journal of Learning Disabilities, 43(1), 32-37.

Barter, B., Hastings, R. P., Williams, R., \& Huws, J. C. (2016). Perceptions and Discourses Relating to Genetic Testing: Interviews with People with Down Syndrome. Journal of Applied Research in Intellectual Disabilities.

Beart, S., Hardy, G., \& Buchan, L. (2004). Changing Selves: A Grounded Theory Account of Belonging to a Self-advocacy Group for People with Intellectual Disabilities. Journal of Applied Research in Intellectual Disabilities, 17(2), 91-100.

Bogart, K. R. (2014). The role of disability self-concept in adaptation to congenital or acquired disability. Rehabilitation Psychology, 59(1), 107-115.

Bogart, K. R. (2015). Disability identity predicts lower anxiety and depression in multiple sclerosis. Rehabilitation Psychology, 60(1), 105-109.
Commented [L18]: Concluding statement and recommendations for future research added in line with reviewer l's comments 
Brocki, J. M., \& Wearden, A. J. (2006). A critical evaluation of the use of interpretative phenomenological analysis (IPA) in health psychology. Psychology and health, 21(1), 87-108.

Brown, J., Dodd, K., \& Vetere, A. (2010). 'I am a normal man': A narrative analysis of the accounts of older people with Down's syndrome who lived in institutionalised settings. British Journal of Learning Disabilities, 38(3), 217-224.

Cakir, S. G. (2014). Ego identity status and psychological well-being among Turkish emerging adults. Identity: An International Journal of Theory and Research, 14(3), 230-239.

Coleman, J. M., Brunell, A. B., \& Haugen, I. M. (2015). Multiple forms of prejudice: How gender and disability stereotypes influence judgments of disabled women and men. Current Psychology, 34(1), 177-189.

Crocker, J., \& Major, B. (1989). Social stigma and self-esteem: The self-protective properties of stigma. Psychological Review, 96, 608-630.

Cunningham, C., \& Glenn, S. (2004). Self-awareness in young adults with Down syndrome: I. Awareness of Down syndrome and disability. International Journal of Disability, Development and Education, 51(4), 335-361.

Findlay, W. M., \& Lyons, E. (2000). Social categorizations, social comparisons and stigma: Presentations of self in people with learning difficulties. British Journal of Social Psychology, 39(1), 129-146.

Fitzgerald, C., \& Withers, P. (2013). 'I don't know what a proper woman means': What women with intellectual disabilities think about sex, sexuality and themselves. British Journal of Learning Disabilities, 41(1), 5-12.

Gilmartin, A., \& Slevin, E. (2010). Being a member of a self-advocacy group: experiences of intellectually disabled people. British Journal of Learning Disabilities, 38(3), 152159.

Goffman, E. (1963). Stigma: Notes on the management of spoiled identity. New York, NY: Simon \& Schuster.

Gould, S., \& Dodd, K. (2014). 'Normal people can have a child but disability can't': The experiences of mothers with mild learning disabilities who have had their children removed. British Journal of Learning Disabilities, 42(1), 27-37.

Harris, P. (1995). Who am I? Concepts of disability and their implications for people with learning difficulties. Disability \& Society, 10(3), 341-351. 
Howland, C. A., \& Rintala, D. H. (2001). Dating behaviors of women with physical disabilities. Sexuality and Disability, 19(1), 41-70.

Jobson, L., Stanbury, A., \& Langdon, P. E. (2013). The Self-and Other-Deception Questionnaires-Intellectual Disabilities (SDQ-ID and ODQ-ID): Component analysis and reliability. Research in developmental disabilities, 34(10), 3576-3582.

Kenyon, E., Beail, N., \& Jackson, T. (2013). Learning disability: Experience of diagnosis. British Journal of Learning Disabilities, 42(4), 257-263.

Li, L., \& Moore, D. (1998). Acceptance of disability and its correlates. The Journal of Social Psychology, 138(1), 13-25.

Mayes, R., Llewellyn, G., \& McConnell, D. (2011). 'That's who I choose to be': The mother identity for women with intellectual disabilities.Women's Studies International Forum, 34(2), 112-120.

McCarthy, M. (2010). Exercising choice and control-Women with learning disabilities and contraception. British Journal of Learning Disabilities, 38(4), 293-302.

McVittie, C., Goodall, K. E., \& McKinlay, A. (2008). Resisting having learning disabilities by managing relative abilities. British Journal of Learning Disabilities, 36(4), 256262.

Mejias, N. J., Gill, C. J., \& Shpigelman, C. (2014). Influence of a support group for young women with disabilities on sense of belonging. Journal of Counseling Psychology, 61(2), 208-220.

Monteleone, R., \& Forrester-Jones, R. (2017). 'Disability Means, um, Dysfunctioning People': A Qualitative Analysis of the Meaning and Experience of Disability among Adults with Intellectual Disabilities. Journal of Applied Research in Intellectual Disabilities, 30(2), 301-315.

Nario-Redmond, M. R. (2010). Cultural stereotypes of disabled and non-disabled men and women: Consensus for global category representations and diagnostic domains. British Journal of Social Psychology, 49(3), 471-488.

Nario-Redmond, M. R., Noel, J. G., \& Fern, E. (2013). Redefining disability, re-imagining the self: Disability identification predicts self-esteem and strategic responses to stigma. Self and Identity, 12(5), 468-488.

Parker, S. E., Mai, C. T., Canfield, M. A., Rickard, R., Wang, Y., Meyer, R. E. \& Correa, A. (2010). Updated national birth prevalence estimates for selected birth defects in the 
United States, 2004-2006. Birth Defects Research Part A: Clinical and Molecular Teratology, 88(12), 1008-1016.

Putnam, M. (2005). Conceptualizing disability: Developing a framework for political disability identity. Journal of Disability Policy Studies, 16(3), 188-198.

Rapley, M., Kiernan, P. \& Antaki, C. (1998). Invisible to themselves or negotiating identity? The interactional management of "being intellectually disabled" Disability \& Society, 13(5), 807-827.

Roizen, N. J., \& Patterson, D. (2003). Down's syndrome. The Lancet, 361(9365), 1281-1289.

Scior, K. (2003). Using Discourse Analysis to Study the Experiences of Women with Learning Disabilities. Disability \& Society, 18(6), 779-795.

Seale, J. K. (2001). The same but different: The use of the personal Home Page by adults with Down Syndrome as a tool for self-presentation. British Journal of Educational Technology, 32(3), 343-352.

Sinason, V. (1992) Mental Handicap and the Human Condition: New Approaches from the Tavistock. London: Free Association Books.

Smart, J. (2008). Disability, society, and the individual (2nd Ed.). Austin, TX: Pro-Ed.

Smith, J., Flowers, P., \& Larkin, M. (2009). Interpretative Phenomenological Analysis: Theory Method and Research. London: Sage.

Starks, H., \& Brown Trinidad, S. (2007). Choose your method: A comparison of phenomenology, discourse analysis, and grounded theory. Qualitative health research, 17(10), 1372-1380.

Tajfel, H., \& Turner, J. (1979). An integrative theory of intergroup conflict. In W. G. Austin \& S. Worchel (Eds.), The social psychology of intergroup relations (pp. 33-48). Monterey, CA: Brooks/Cole.

Traustadottir, R. \& Johnson, K. (2000). Women with Intellectual Disabilities: Finding a Place in the World. London: Jessica Kingsley Publications.

Valeras, A. (2010). "We don't have a box": Understanding Hidden Disability Identity Utilizing Narrative Research Methodology. Disability Studies Quarterly, 30(3), 12671297.

Van Manen, M. (1997). Researching lived experience: human science for an action sensitive

Vleioras, G., \& Bosma, H. A. (2005). Are identity styles important for psychological wellbeing? Journal of Adolescence, 28(3), 397-409. 
Wehmeyer, M. L. \& Garner, N.W. (2003). The impact of personal characteristics of people with intellectual and developmental disability on self-determination and autonomous functioning. Journal of Applied Research in Intellectual Disabilities, 16(4), 255-265.

Wilkinson, V. J., Theodore, K., \& Raczka, R. (2015). 'As normal as possible': Sexual identity development in people with intellectual disabilities transitioning to adulthood. Sexuality and Disability, 33(1), 93-105.

Zolkowska, T., \& Kaliszewska, K. (2014). The social construction of social identity of people with intellectual disability. International Journal of Developmental Disabilities, 60(1), 3-12. 